\title{
Same-different judgments with words and nonwords: The differential effects of relative size
}

\author{
DEREK BESNER and MAX COLTHEART \\ Reading University, Whiteknights, Reading, RG6 2AL England
}

\begin{abstract}
Words were paired with words and nonwords with nonwords in a simultaneous matching task requiring a same-different judgment. A difference in size slowed "same" RTs for both words and nonwords, while "differ" RTs for both words and nonwords were unaffected. These results do not support Bruder and Silverman's 1974 conclusion that the word processing system filters size. The effects of relative size differences were discussed in terms of (a) normalization procedures and (b) changes in states of evidence leading to alterations in a response selection stage.
\end{abstract}

Posner and Mitchell (1967) have concluded that stimuli can be classified on the basis of two independent criteria; one related to physical identity, the other dependent upon name identity. Illustrations of these levels of processing come from repeated demonstrations that a pair of letters can be classified as "same" much faster if they are physically identical (e.g., AA) than if they are only nominally equivalent (e.g., Aa).

The traditional problem of stimulus equivalence concerns how it is possible to classify objects as "same" despite variations such as size or brightness. Does a size difference preclude a "same" classification based on a visual code, such that "cC" or "Oo" can only be deemed "same" by recourse to the name code, or alternatively, can the visual code ignore size variations (as if it were a size-free representation and hence somewhat abstract)?

The results of several experiments (Corcoran \& Besner, 1975; Posner \& Mitchell, 1967) suggest that neither is the case; "same" classifications to letter pairs like "Cc" are faster than name matches but $20-40 \mathrm{msec}$ slower than physically identical pairs. Posner referred to these matches as "analog matches" and suggested that such matches would "require an additional visual process to equate two letters which differ in size" (Posner, 1973) and would "depend upon operations like size variation which can be performed within the visual system and need not require contact with past experience" (Posner, 1969).

Bruder and Silverman (1974) extended this work by studying physical, analog, and name matching of words and nonwords. They obtained the surprising result that "same" RTs to analog and physical matches differed for nonwords but not for words. They proposed two possible explanations for the absence of an analog effect on word matching. First, perhaps words and nonwords are processed in different ways or in different places (e.g., different cerebral hemispheres) and the word

Reprint requests should be sent to Derek Besner, Department of Psychology, University of Reading. Whiteknights, Reading, RG6 2AL, England. We thank Leslie Henderson and Eileen Davelaar for their comments and editorial assistance. processing system is capable of filtering out size variations, whilst the nonword processing system cannot do so.

The second proposal they consider assumes that physical and abstract properties of words are processed in parallel. The fact that words are matched faster than nonwords (e.g., Barron \& Pittenger, 1974; Eichelman, 1970 ) is attributed to a redundancy gain resulting from the inclusion of abstract features in the matching process. In this model, the observation that physical matches are faster than name matches is supposed to stem from physical comparisons indicating that differences exist.

It seems rather important to decide whether analog effects occur in word matching; if they do not, this suggests that there may be qualitative differences in the way words and nonwords are processed, and if this were so, the relevance of much recent work on visual information processing to everyday word recognition and reading could be challenged since most of this work has used nonword stimuli.

Bruder and Silverman's study is unsatisfactory on several counts. One problem is that the number of readings obtained for each condition was rather low, median RTs being based on four or fewer correct responses. A further problem is that the inclusion of words in different cases may have biased the subjects to perform the task, at least some of the time, by naming the words instead of matching them visually. This might account for their finding that for three-letter words, physical match times were no faster than name match times. If names are being matched, it should come as no surprise that size has no effect; name matches are presumably based on a phonological code in which visual parameters such as size are not represented (Corcoran \& Besner, 1975).

The present study compared matching times for word and nonword strings of four letters. The size condition was such that the letters differed in height by $50 \%$. Each condition contained 16 readings per subject. The stimuli were always uppercase. 
Table 1

Median, Mean, and Minimum Reaction Time in Milliseconds According to Condition

\begin{tabular}{lccc}
\hline & $\begin{array}{c}\text { Large } \\
\text { Large }\end{array}$ & $\begin{array}{l}\text { Small } \\
\text { Small }\end{array}$ & $\begin{array}{l}\text { Large } \\
\text { Small }\end{array}$ \\
\hline Words & \multicolumn{3}{c}{ Same Response } \\
$\quad$ Median & 446 & 449 & 501 \\
Mean & 448 & 464 & 507 \\
$\quad$ Minimum & 404 & 403 & 436 \\
Nonwords & & & \\
$\quad$ Median & 473 & 495 & 552 \\
Mean & 483 & 503 & 565 \\
$\quad$ Minimum & 422 & 439 & 497 \\
Words & & Different Response \\
$\quad$ Median & 500 & 530 & 499 \\
$\quad$ Mean & 509 & 538 & 511 \\
$\quad$ Minimum & 451 & 479 & 446 \\
Nonwords & & & \\
$\quad$ Median & 487 & 526 & 503 \\
$\quad$ Mean & 499 & 533 & 519 \\
$\quad$ Minimum & 432 & 461 & 432 \\
\hline
\end{tabular}

\section{METHOD}

\section{Stimulus Materials}

The basic stimuli comprised 16 four-letter words and 16 four-letter nonwords composed of consonants and vowels. These were organized in pairs such that words were always paired with words, and nonwords with nonwords. The stimulus set may be seen in the appendix.

The experiment was a totally within design that contained three variables: familiarity (word, nonword), size (same, different), and response type (same, different). The visual angle was approximately $.77 \mathrm{deg}$ high by $1.05 \mathrm{deg}$ wide for any pair of letter strings. This was accomplished by having the computer set the string slightly further away from the fixation point when the size was smaller. Thus, visual angle of the array did not change over the course of the experiment.

Each word appearing once paired with itself in each condition comprised the "same" responses. "Different" response pairs consisted of each of the 16 words paired twice in a random fashion with the constraint that the second pairing was always with a different word. Each of the 16 "differ" pairs appeared once in every condition. "Same" and "differ" pairs that were nonwords were constructed in an identical fashic. with the same constraints.

There were a total of 232 trials split evenly between two lists. Each list contained 16 trials per condition, of which half required a "same" response and half a "different" response. There were three size conditions: Large/large, small/small, and large/small. All the factors were random in that no variable was blocked during presentation. The exception was that response type was subject to the constraint that no more than four trials occurred successively where the correct answer was a repetition of one particular response.

\section{Procedure}

Subjects were seated in a darkened room at a table facing a CRT slaved to a PDP 12 computer. A small panel in front of the subject contained three buttons, two of which were response keys, while the remaining key under subject control initiated each trial. At the start of a trial, a fixation point consisting of an $X$ appeared on the screen. Depressing the start button terminated the 'ixation point, and 500 msec later a pair of letter strings were displayed, one immediately above the fixation point, the other immediately below. The display terminated when the subject made a response. The intertrial interval, varied since the beginning of each trial, depended upon the subject pressing the start button. The average time was 12 to $15 \mathrm{~min}$ for the entire experiment.

The subjects were instructed to respond "same" if the letters were the same in both rows, "differ" otherwise. They were informed what constituted the stimulus population, response probability, number of practice trials, and the total number of trials. They were further instructed that size was irrelevant to the correct response, and that all of the stimuli consisted of uppercase letters. Speed was requested, but at the same time, subjects were cautioned to keep their error rate below $10 \%$. All subjects responded "same" with their preferred hand and "differ" with their nonpreferred hand.

Subjects viewed one list of 116 trials, the first 20 of which were practice trials composed of four-letter words and nonwords that never appeared subsequently. A 2-min pause intervened between List 1 and the start of List 2 . The first 20 trials of List 2 were also practice ones.

The nine subjects who participated in the experiment all served without pay and were drawn from a long-suffering collection of graduate students, research assistants, and staff.

RTs for the practice trials and incorrect responses were discarded before submitting the data to an analysis of variance. Mean, median, and minimum RT, where the minimum RT was based on the mean of the six fastest RTs, as well as the distribution of errors across conditions, can be seen in Tables 1 and 2 . Only the results of the mean RT analysis are reported since the other analy ses yielded similar conclusions.

\section{"Same" Responses}

Clark (1973) has pointed out that most analyses fail to establish generality over both subjects and items simultaneously, since items are generally treated as a fixed effect rather than a random effect. It may thus be the case that when a small fixed sample of items is used for each subject, replication with a different sample of items may well fail to observe the same effects. For this reason the data was analyzed using the $\min \mathrm{F}^{\prime}$ procedure described by Clark (1973).

Familiarity was a main effect, words being faster than nonwords, $\min F^{\prime}(1,31)=12.00, p<.01$. Size was also a main effect, $\min F^{\prime}(2,63)=27.50, p<.01$. The interaction of Size and Familiarity was not significant, $\min F^{\prime}(2,63)=1.79$, $p>.05$; however, eight out of nine subjects showed a size effect that was smaller for words than for nonwords.

A second experiment was run in order to establish whether this interaction trend would stand up under more favorable conditions. The experiment was a replication of Experiment 1 using the same stimuli with the exception that the size difference was $20 \%$ rather than $50 \%$. The results can be seen in Tables 3 and 4.

Clearly, nonwords still show an effect of size although the magnitude of the effect is reduced by almost a half. Of the 10 subjects, 9 were slower to respond "same" to different sized nonword pairs than to same sized nonword pairs. In contrast,

Table 2

Percentage Errors Per Condition

\begin{tabular}{lccc}
\hline & $\begin{array}{l}\text { Large } \\
\text { Large }\end{array}$ & $\begin{array}{l}\text { Small } \\
\text { Small }\end{array}$ & $\begin{array}{c}\text { Large } \\
\text { Small }\end{array}$ \\
\hline Words & & & \\
$\quad$ False same & 2.0 & 16.0 & 1.5 \\
$\quad$ False differ & 2.0 & 3.4 & 4.0 \\
Nonwords & & & \\
$\quad$ False same & 2.7 & 8.7 & .6 \\
$\quad$ False differ & 3.4 & 8.0 & 19.4 \\
\hline
\end{tabular}


there was no effect of size on the time to match word pairs. It seems a reasonable conclusion that words are less affected by size variations than are nonwords.

The "differ" response data contrasted sharply with those for the "same" data; detecting that strings were different was equally fast for words and nonwords. More importantly, differences in size had no effect on the time to make a "differ" judgment for words or nonwords, either in Experiment 1 or Experiment 2.

\section{DISCUSSION}

These results do not agree with Bruder and Silverman's (1974) conclusions that the system responsible for processing words is impervious to size variations. The time to judge letter strings as "same" was clearly affected by a difference in relative size, regardless of whether the strings were words or nonwords. A second finding of importance is that size differences did not affect the time to classify letter strings as different.

The finding that "differ" judgments are unaffected by size variations raises some questions concerning the nature of the evidence that purports to support the hypothesized analog normalization process. Without exception, the literature that supports such an interpretation (Corcoran \& Besner, 1974; Posner \& Mitchell, 1967; Sekuler \& Nash, 1972) is based on the observation that "same" RTs increase when stimuli are different sized. None of these experiments have reported how size differences affect "differ" judgments.

If normalization is an early process that operates prior to the comparison stage, then we would expect that normalizing the representation should incur equal time costs for the decisions "same" and "different." This expectation has not been confirmed. Besner and Coltheart (1974) found that while "same" RTs varied as an increasing function of the magnitude of the size difference, "differ" judgments were completely unaffected by such a manipulation. Moreover, this result was obtained with several different stimulus populations, suggesting that simple explanations such as nominal coding or the operation of a deadline clock are unlikely candidates for accounting for why "different" judgments are unaffected by size variations. Separate

Table 3

Median, Mean, and Minimum Reaction Time in Milliseconds According to Condition

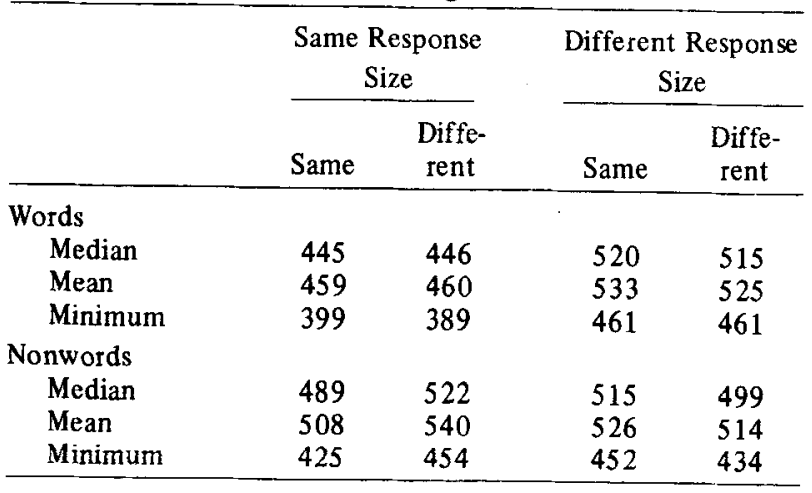

Table 4

Percentage Errors Per Condition

\begin{tabular}{ccc} 
& Same & Different \\
& Size & Size \\
\hline
\end{tabular}

Words $\begin{array}{lll}\text { False same } & 2.5 & 2.5\end{array}$ $\begin{array}{lll}\text { False differ } & 8 & 4.5\end{array}$

Nonwords

$\begin{array}{llr}\text { False same } & 8 & 4.4 \\ \text { False differ } & 6 & 12.5\end{array}$

experiments with letters, geometric forms, and a large pool of nonsense shapes all yielded identical findings; "same" RTs increased in proportion to the magnitude of the size difference, while "differ" RTs remained unaffected.

If normalization is thought to be a preprocessing stage, it is difficult to understand why normalizing for size fails to incur time costs for the "different" judgment. In character classification studies such as those of Bracey (1969), Nickerson (1975), and Sternberg (1967), where visual noise is filtered (obviously a preprocessing stage), both types of judgments are affected by an equal amount.

One possible salvation for the normalization hypothesis is to assume that there are two analyzing systems underlying the judgments "same" and "different." Such a possibility has been suggested in various forms by Bamber (1969), Egeth and Blecker (1971), and Sekuler (1965). One might further suppose that the judgmental process responsible for "same" decisions is a wholistic process that is template based and consequently requires normalizing routines in order to match stimuli that do not overlap spatially because of being different sized. The mechanism that yields "different" judgments may, in contrast, be a more analytic process, one, say, that looks for differences in line orientation, or computes area judgments for separate portions of each stimulus and then compares these. The existence of separate and qualitatively distinct matching mechanisms, in and by itself, would not however be sufficient since whatever is responsible for normalizing must logically operate prior to matching. One interesting implication of this is that these separate matching mechanisms may each analyze separate and different representations.

If the observed increase in RT is not due to the operation of a normalization process, what might constitute an alternative explanation? One possibility is to assume that the processing system treats size as an irrelevant dimension rather than as a component that requires normalization. If the "same" system is either a parallel or serial mechanism that processes exhaustively, then the presence of a dimension that is different in state from other features such as shape could serve to reduce a "sameness quotient" computed in a response organization and selection stage. Response speed may 
thus be slowed when the sameness quotient is less than unity. When all the dimensions agree in state (such as when letter strings are the same both in shape and size), no such problem arises because the sameness quotient is not less than unity.

The failure of size to affect "different" judgments can be accommodated by assuming that the system self-terminates as soon as a difference between relevant features is found. As long as the system is parallel and self-terminating, with nonoverlapping finishing times for different dimensions, then if size processing finishes after relevant features that indicate a difference have been processed, there will never be an effect of size since the system will have self-terminated before having finished processing the size dimension. This logic applies equally well to a system that might be serial and self-terminating, given the proviso that feature examination is ordered such that shape features are examined before size features. ${ }^{2}$

Whether this evidence analysis of the situation proves correct or not remains to be seen; it does seem clear, however, that "analog matches" are not produced by a process which makes a preliminary size adjustment on a common representation (since this would affect both "same" and "different" judgments), nor by a process which does not interact with past experience (since the magnitude of the size effect is not the same for words and nonwords).

Finally, why is word matching so often found to be faster than nonword matching? One explanation that has been advanced (e.g., Barron and Pittenger, 1974; Henderson, 1974) is that meaning may at least partly mediate a "same" decision. One way to conceptualize this is to think of two ongoing processes of analysis; (a) a visual comparison and (b) a semantic comparison. If the finishing times for these two processes overlap so that some of the time a semantic comparison finishes prior to a visual comparison, then a word superiority effect (WSE) follows because nonwords have no semantic correlates; hence finishing times for nonwords are drawn from only one distribution, that of the visual comparison process.

If we now introduce a variable, such as differential size, that slows the visual comparison process but not the semantic analysis, it follows that the WSE should be larger for stimuli that are different sized than for stimuli that are same sized. This is because anything that slows the visual analysis without affecting the semantic analysis increases the probability that the semantic analysis will finish prior to the visual analysis, thus generating a larger statistical redundancy effect. Although the interaction was not significant, note that the mean value for the WSE is approximately $20 \mathrm{msec}$ larger for different-sized stimuli than for same-sized stimuli.

If the magnitude of the size difference between stimuli is now reduced as in Experiment 2, then we should expect that (a) the WSE should still be larger for different-sized stimuli than same-sized stimuli, (b) the magnitude of the size effect itself should be reduced relative to Experiment 1, and (c) the magnitude of the change in the WSE for different-sized vs. same-sized stimuli should be smaller than its counterpart in Experiment 1.

Some calculations from Tables 1 and 3 indicate that while (a) and (b) are true, (c) is not; indeed it is even in the wrong direction. These effects are very small, on the order of 10-20 msec and involve comparisons across experiments. They do not bear up under statistical scrutiny; consequently we should be extremely cautious about rejecting a dual process overlapping distributions model in its present form. It does suggest, however tentatively, that embedding dual processing notions within a model that generates a WSE only by recourse to overlapping distributions may be an insufficient explanation. ${ }^{3}$

\section{REFERENCES}

Bamber, D. Reaction time and error rates for "same"_cdifferent" judgements of multidimensional stimuli. Perception \& Psychophysics, 1969, 6, 169-174.

Barron, R., \& Pittenger, J. B. The effect of orthographic structure and lexical meaning on same-different judgments. Quarterly Journal of Experimental Psychology, 1974, 26. 566-581.

Besner, D., \& Coltheart, M. Asymmetry in binary clasaification: The effects of relative size on reaction time. Paper presented at Canadian Psychological Association, 1974, Windsor, Canada.

Bracey, E. W. Two operations in character recognition: A partial replication. Perception \& Psy chophysics, 1969, 6, 357-360.

Bruder, E., \& Silverman, W. Effects of familiarity and sequence length on analog matching in the simultaneous matching task.

\section{APPENDIX}

DIFFER Nonword Pairs

$\begin{array}{llllllll}\text { HTRE } & \text { EDLH } & \text { RHBA } & \text { BRDE } & \text { EDLH } & \text { BRDA } & \text { HRTA } & \text { BRDA } \\ \text { RBLA } & \text { HTDA } & \text { HTDA } & \text { RBLA } & \text { HTRE } & \text { TDBE } & \text { ELBT } & \text { ELBT } \\ \text { TDBE } & \text { LHBA } & \text { ABRT } & \text { ERDA } & \text { ERDA } & \text { EBTL } & \text { LHBA } & \text { RHBA } \\ \text { HRTA } & \text { ABRT } & \text { HRBE } & \text { DTRE } & \text { BRDE } & \text { HRBE } & \text { EBTL } & \text { DTRE } \\ & & & \text { DIFFER } & \text { Word Pairs } & & & \\ \text { BEAT } & \text { BEER } & \text { BARE } & \text { BATH } & \text { BALL } & \text { DEBT } & \text { HARE } & \text { HEAT } \\ \text { LEAD } & \text { LARD } & \text { REAL } & \text { LATE } & \text { DARE } & \text { HARD } & \text { THAT } & \text { DRAB } \\ \text { LATE } & \text { DEBT } & \text { REAL } & \text { DARE } & \text { HARE } & \text { HARD } & \text { LARD } & \text { BEAT } \\ \text { BALL } & \text { LEAD } & \text { THAT } & \text { HEAT } & \text { BATH } & \text { BEER } & \text { BARE } & \text { DRAB }\end{array}$


Joumal of Experimental Psychology, 1974, 102, 875-880.

Clark, H. H. The language-as-fixed effect fallacy: A critique of language statistics in psychological research. Journal of Verbal Learning and Verbal Behaviour, 1973, 12, 335-359.

Corcoran, D. W. J., \& Besner, D. Application of the Posner technique to the study of size and brightness irrelevancies. In P. M. A. Rabbitt and S. Dornic (Eds.), Attention and Performance $V$. London: Academic Press, 1975.

Egeth, H., \& Blecker, D. Differential effects of familiarity on judgements of sameness and difference. Perception \& Psychophysics, $1971,9,321-326$.

Eichelman, W. Familiarity effects in the simultaneous matching task. Journal of Experimental Psychology, 1970, 86, 275-282.

Henderson, L. A word superiority effect without orthographic assistance. Quarterly Journal of Psychology, 1974, 26, 301-311.

Nickerson, R. W. Effects of correlated and uncorrelated noise on visual pattern matching. P. M. A. Rabbitt and S. Dornic (Eds.), Attention and Performance $V$. London: Academic Press, 1975.

Posner, M. I. Abstraction and the process of recognition. G. Bower (Ed.), Advances in learning. New York: Academic Press, 1969.

Posner, M. I. Cognition: An introduction. Elenview, Illinois: Scott Foreman. Brighton, England, 1973.

Posner, M. I., \& Mitchell. R. Chronometric analysis of classification. Psychological Review, 1967, 74, 392-409

Sekuler, R. Signal detection, choice response times, and visual backward masking. Canadian Journal of Psychology, 1965, 19, 118-132.

Sekuler, R., \& Nash, D. Speed of size scaling in human vision. Psychonomic Science, 1972, 27, 93-94.
Stemberg, S. Two operations in character recognition. Wathen-Dunn (Ed.), Models for the perception of speech and form. M.I.T. Press, 1967.

\section{NOTE}

1. False "same" errors for the small/small condition are somewhat high. A check of the data indicated that this was due mainly to two subjects making a large number of errors. A reanalysis of the data excluding these subjects left the pattern of results unchanged. The large number of false "differ" errors for inspection of the data suggests that most errors occurred toward the end of the experimental session. The error patterms from Besner and Coltheart (1974) are quite similar but not as exaggerated.

2. The fact that "same" judgments are often found to be faster than "different" judgments may only reflect the possibility that "same" judgments are executed faster rather than implying the existence of separate sy stems of analysis.

3. One way of retaining the dual processing hypothesis without the differential finishing time rule is to assume that the "same" counter sums visual and semantic information so that response time decreases $w$ ith increases in the total amount of information indicating sameness.

(Received for publication November 25, 1974; accepted December $7,1974$. ) 